\title{
Retinyl Palmitate Measurement
}

National Cancer Institute

\section{Source}

National Cancer Institute. Retinyl Palmitate Measurement. NCI Thesaurus. Code C135442.

The determination of the amount of endogenous retinyl palmitate in a biological sample. 